\title{
Binocular View to Pathogenesis of Amblyopia
}

\author{
Maghlakelidze Natalia ${ }^{1 *}$, Zueva Marina $V^{2}$ and Petriashvili G ${ }^{1}$ \\ ${ }^{1}$ Department of Ophthalmology, "Aversi Clinic" Ltd, Georgia \\ ${ }^{2}$ Department of Clinical Physiology of Vision, Federal State Budgetary Institution, Russia
}

Submission: October 12. 2017; Published: November 14, 2017

*Corresponding author: Maghlakelize N, Pediatric ophthalmologyst Surgeon, Department of Ophthalmology, "Aversi Clinic" Ltd, Vazha-Pshavela Ave, №27b, Tbilisi, Georgia, Tel: +995-595-674787; Email: 797909@bk.ru

\begin{abstract}
The review presents new ideas about the mechanisms of development of amblyopia, which are currently discussing in the literature. By now, objective evidence has accumulated that amblyopia develops both monocular and binocular deficiencies in visual processing, a decrease of the monocular visual acuity and a violation of binocular and stereoscopic vision. Given the increasing evidence of fundamental and clinical research, it is most likely that binocular dysfunction is primary, and monocular reduction in visual acuity is secondary to this disease. Amblyopia is a binocular pathology, and binocular interaction seems to play a critical role in the pathogenesis of strabismic, anisometropic and combined amblyopia. Given this, it seems appropriate to begin treatment with the restoration of binocular vision, which also leads to the restoration of the vision of the amblyopic eye. Visual dysfunction in amblyopia is often associated with the emergence of severe suppression when looking with both eyes. Suppression makes the structurally binocular system functionally monocular. Therefore, the first and most necessary step to restore binocular vision should be considered the elimination of suppression. The quantification of suppression is a critically important step for the development of new therapies for amblyopia based on the global perception of movement associated with the function of the dorsal extrastriate visual cortex. This conceptually new understanding of amblyopia now becomes the basis for carrying out a large volume of diverse studies that provide the development of more effective therapies that will primarily focus on eliminating suppression and restoring binocular vision.
\end{abstract}

\section{Introduction}

Amblyopia is a postnatal violation of a development of the visual cortex due to abnormal visual experience during the critical period in infancy or early childhood (the first $7-10$ years) and leads to the chronic insufficiency of cortical processes, even after the elimination of the amblyogenic factor $[1,2]$.

Amblyopia affects 3-5\% of the population [3]. According to the etiological factor, it is divided to anisometropic, strabismic, deprivational due to cataracts or ptosis, and mixed amblyopia. The most common amblyogenic factors are strabismus, anisometropia, and deprivation. In the presence of several amblyogenic factors speak mixed mechanism of amblyopia. The most common is strabismic amblyopia with anisometropia [4-6].

The pathogenetic mechanisms of amblyopia have not been sufficiently studied, despite the data of numerous electrophysiological and psychophysical studies and the presence of ultramodern methods of neuroimaging, for example, functional magnetic resonance imaging (fMRI). Until now, it remains unclear whether there are different or a single pathogenetic mechanism for the development of the various types of amblyopia.
Because amblyopia often involves one eye, it is related to a monocular pathology, and accordingly, the treatment is also monocular. The primary methods of treatment amblyopia are the occlusion of the «healthy» eye and penalization. However, monocular therapy for amblyopia has recently been questioned due to the frequent recurrence of amblyopia after the occlusion was stopped and the presence of residual amblyopia [2].

\section{The current hypothesis about the pathogenesis of amblyopia}

According to the currently accepted belief, amblyopia arises from a lack of consistency between the images of each eye; information from one eye becomes more privileged, while the picture coming from the other eye is actively suppressed by the visual cortex [7]. Suppression leads to decreased visual acuity in this eye and, therefore, disrupts binocular vision. However, the question arises whether low visual acuity is the cause or consequence of a violation of binocular vision? According to the recently proposed hypothesis, the primary and leading factor in the development of amblyopia is the disruption of binocular vision, which leads to suppression with further development of 
visual loss [2,8]). The new hypothesis lays the foundation for an alternative approach to developing more effective treatment for amblyopia.

\section{Association between amblyopia and binocular vision}

Alterations in the primary and secondary visual cortex of patients with amblyopia have been shown in numerous studies [9-15]. Recent evidence suggests that in amblyopic patients, there is a deficit of processing of visual information at high levels of the visual system, in the areas of the parietaloccipital and temporal cortex [16]. These areas of higher level of the visual system processing the binocular signal are part of the cortical neural network involved in the 3D vision of the object. The study of the visual cortex of the brain revealed a reduction in the number of binocularly controlled neurons in the primary visual cortex V1 and a decrease in the number of neurons controlled by the amblyopic eye $[17,18]$. It was found that weakening of binocular cortical connections [19] can cause a violation of fixation of one eye with strabismus $[9,20]$. Other authors investigated the binocular interaction in the $\mathrm{V} 1$ region and found a reinforcement of binocular suppression [21,22]. An increase of suppression may be associated with a decrease the number of binocularly controlled neurons in the $\mathrm{V} 1$ region, as earlier studies have shown that weakening of suppression by the bicuculline promoted the recovery of more than half of the cortical neurons [23]. Numerous of electrophysiological studies have shown a decrease of amplitude of visual cortical evoked potentials (VEP) and their normal or elongated peak latency when stimulating the amblyopic eye [15,24-26]. Thus, a decrease in the response of the visual cortex may be due to a disruption of binocular vision in patients with amblyopia. Strabismic and anisometropic amblyopia are characterized by different patterns of visual deficits. Strabismic amblyopia is associated with a disproportional visual impairment inoptotype visual acuity and vernier acuity, compared with grating acuity, but anisometropic amblyopia is associated with proportional deficits in optotype, vernier and grating acuity $[27,28]$. The difference in the patterns of visual deficits between the strabismic and anisometropic amblyopia can talk about various pathophysiological processes (the etiological hypothesis) [29].

The second (age) hypothesis implies that the degree of various spatial deficiencies with strabismic and anisometropic amblyopia depends on the onset of the disease, that is, of the level of maturation of the visual system [29]. Anisometropic amblyopia develops later when the visual system is more developed, and the binocular system is more or less formed. Therefore, disturbances of visual functions are weaker in comparison with the strabismic amblyopia.

E. Birch with colleagues investigated the visual acuity in optotypes, vernier, and grating in patients with amblyopia, which developed at different stages of visual maturation: in infancy and preschool age, taking into account the exact onset of the disease and etiology [30]. They observed that in the case of strabismic amblyopia, which arose both in infancy and preschool age, there was a disproportionately large deficit of visual acuity in optotype and vernier in comparison with grating acuity. When analyzing the data obtained in the infantile group, different patterns of visual deficits were found in patients with strabismic and anisometropic amblyopia. Children with infantile strabismic amblyopia showed a disproportionately high visual acuity deficiency in optotypes and vernier as compared with grating acuity, and children with infantile anisometropic amblyopia showed a proportional impairment of the same functions. The researchers concluded that binocularity is the leading factor of visual deficiency in these patients.

In macaques with experimentally induced anisometropia, the blurred vision of one eye leads to a selective loss of neurons responding to high spatial frequencies [31,32]. On the other hand, infantile strabismus disrupts the binocular connections of the cortical neurons and can lead to the development of a preferential fixation of one eye and some disturbances of monocular functions in the non-dominant eye, where visual acuity is specifically severe in optotypes and vernier [33]. These facts indicate that the presence or absence of binocular function but not of strabismus drives the pattern of visual deficits.

According to E Birch et al. [2], regardless of the etiology of amblyopia, those patients who do not have stereoscopic vision give a disproportionate deficiency of visual acuity in optotypes compared to patients with stereoscopic vision. Visual acuity with amblyopia correlates with binocular status; in the absence of binocular vision in patients, as a rule, there is low visual acuity [34]. The violation of stereoscopic vision also depends on the type of amblyopia and is more often disturbed in the case of strabismic than with anisometropic amblyopia [34]. These research results led to a new approach to the treatment of amblyopia to eliminate suppression in the visual cortex of the brain. Suppression is the strongest inhibiting factor concerning recovery of binocular vision, and its elimination is an indispensable first step in any binocular therapy $[35,36]$.

\section{Suppression and visual processing with amblyopia}

Suppression plays a significant role in the disturbance of monocular and binocular visual functions in patients with amblyopia [37]. Under suppression, we mean the inhibitory effect of the paired eye on the amblyopic eye when looking with both eyes. Suppression inhibits information from the amblyopic eye to prevent diplopia or confusion. When images of one object fall onto non-corresponding areas of the retina of two eyes in the primary visual cortex, it is projected accordingly into disparate areas and causes diplopia. When different images hit the corresponding retinal points, they are projected into the same area of the cerebral cortex, as a result, which causes confusion. In the 1930-80's suppression was an actual topic raised in many works. The functional scotoma, its size, and location for various types of strabismus were carefully examined. It is believed that the scotoma involves that part of the visual field of the 
declined eye that corresponds to the foveal area of the fixing eye. Sometimes the scotoma widens and includes the foveal region of the deflected eye.

Recently, there has been a sharp revival of interest in suppression research, which radically changed the notion of suppression, and offered new and much less dichoptic ways of measuring it [39]. Previously, suppression was determined only qualitatively, it was possible to detect its presence or absence with tests of Worth or the Bogolini, etc.

To date, methods for quantifying suppression are based on the global visual processing. Anomalous of visual processing can be associated with a violation of the perception of individual elements of the visual scene (local processing), and with a defect in the integration of multiple elements and image parameters in space and time (global processing) [40]. The deficit of the local processing is often associated with a violation in the primary visual cortex V1, where the cells with relatively small receptive fields are located. On the other hand, disturbances in the global processing of visual information are believed to be associated with the involvement of extra-cortical areas. Neurons in these zones have large receptive fields, can integrate signals coming from the lower levels of the visual system, and play a significant role in the segregation of the signal and noise [41]. In the local processing, spatial and temporal processing is singled out.

Psychophysical studies have shown that amblyopia affects many aspects of spatial vision: contrast sensitivity, hyperacuity, crowding-effect [42]. That is, the parvocellular pathway is interested. Unlike local spatial processes, local temporal processingis less altered in amblyopia. Global processing of visual information is considered within the framework of the parallel information processing hypothesis [43-45].

According to this hypothesis, the dorsal extrastriate visual regions sensitive to movement of the V5 / MT zone (middle temporal) are specialized for the perception of the localization and displacement of objects, and, therefore, provides the basis for visual-motor coordination. This pathway of processing of the visual information is called the dorsal stream (the pathway «where» or «vision for action»). It extends from the occipital lobe to the parietal lobe and represents a continuation of the magnocellular pathway. The second pathway, known as the ventral stream (the «what» or «vision for recognition» pathway), includes the ventral areas of the occipital and temporal lobes $[46,47]$. The connections and structures of this pathway specialize in processing a form that supports object recognition and represents the continuation of the parvocellular pathway.

Recently, convincing evidence has appeared that in addition to anomalous local spatial processing, there is a deficit of global perception of movement, that is, of temporal processing, which does not depend on the local processing of visual information. The evidence for a deficit for the global perception of a form of the object is less convincing than for the movement [48-50].
It is particularly interesting taking into account the wellknown hypothesis suggested that local temporal processes are less affected by amblyopia than local spatial processes. It is surprising that the patterns of deficiency of local processing do not correspond to the patterns of a deficit of global processing in monolateral amblyopia. The deficit of global information processing is present only in tasks requiring the isolation of a signal from noise. It turns out that the dorsal extra-striate visual cortex is susceptible to the influence of abnormal developments to a more significant than the ventral region [51]. Recent work has shown that suppression in amblyopia is most pronounced in the dorsal than in the ventral flow [52], so the authors proposed a method for determining suppression in patients with anisometropic and strabismic amblyopia based on the global movement of kinematogram dots.

\section{Conclusion}

a) By now, objective evidence has been accumulated that amblyopia is a binocular pathology. Binocular interaction plays a critical role in the pathogenesis of strabismic, anisometropic and combined amblyopia.

b) Binocular dysfunction can be primary, and a monocular decrease of visual acuity - secondary. Therefore, it is recommended to start the treatment with the restoration of binocular vision, which also can lead to the recovery of the visual acuity of the amblyopic eye.

c) The elimination of suppression should be considered as a first and most necessary step to restore binocular vision. Suppression renders a structurally binocular system functionally monocular.

d) Quantitative evaluation of suppression is the primary step in developing new methods for the treatment of amblyopia, based on the perception of global movement associated with the function of the extra-ridge dorsal visual cortex.

e) This new understanding of amblyopia provides the basis for carrying out a large volume of further research and developing more effective therapies that will primarily focus on eliminating suppression and restoring binocular vision.

\section{References}

1. Wong AM (2012) New concepts concerning the neural mechanisms of amblyopia and their clinical implications. Can J Ophthalmol 47(5): 399-409.

2. Birch EE (2013) Amblyopia and binocular vision. Prog Retin Eye Res 33: 67-84.

3. Brown SA, Weih LM, Fu CL, Dimitrov P, Taylor HR, et al. (2000) Prevalence of amblyopis and associated refractive errors in an adult population in Victoria, Australia. Ophthal Epidemiol 7(4): 249-258.

4. Simons K (2005) Amblyopia characterization, treatment, and prophylaxis. Surv Ophthalmol 50(2): 123-166.

5. Holmes JM, Clarke MP (2006) Amblyopia. Lancet 367(9519): 13431351. 
6. Wu C, Hunter DG (2006) Amblyopia: diagnostic and therapeutic options. Am J Ophthalmol 141(1): 175-184.

7. Harrad R, Sengpiel F, Blakemore C (1996) Physiology of suppression in strabismic amblyopia. Br J Ophthalmol 80(4): 373-377.

8. Hess RF, Thompson B (2015) Amblyopia and the binocular approach to its therapy. Vision Res 114: 4-16.

9. Kiorpes L, Kiper DC, O’Keefe LP, Cavanaugh JR, Movshon JA (1988) Neuronal correlates of amblyopia in the visual cortex of macaque monkeys with experimental strabismus and anisometropia. J Neurosci 18(16): 6411-6424.

10. Imamura K, Richter H, Fischer H, Lennerstrand G, Franzén O, et al. (1997) Reduced activity in the extrastriate visual cortex of individuals with strabismic amblyopia. Neurosci Lett 225(3): 173-176.

11. Demer JL, von Noorden GK, Volkow ND, Gould KL (1988) Imaging of cerebral blood flow and metabolism in amblyopia by positron emission tomography. Am J Ophthalmol 105(4): 337-347.

12. Kabasakal L, Devranoğlu K, Arslan O, Erdil TY, Sönmezoğlu K, et al. (1995) Brain SPECT evaluation of the visual cortex in amblyopia. J Nucl Med 36(7): 1170-1174.

13. Anderson SJ, Holliday IE, Harding GF (1999) Assessment of cortical dysfunction in human strabismic amblyopia using magnetoencephalography (MEG). Vision Res 39(9): 1723-1738.

14. Levi DM, Manny RE (1982) The pathophysiology of amblyopia: Electrophysiological studies. Ann N Y Acad Sci 388: 243-263.

15. Kubová Z, Kuba M, Juran J, Blakemore C (1996) Is the motion system relatively spared in amblyopia? Evidence from cortical evoked potentials. Vision Res 36(1): 181-190.

16. Joly O, Frankó E (2014) Neuroimaging of amblyopia and binocular vision: a review. Front Integr Neurosci 8: 62.

17. Wiesel TN, Hubel DH (1963) Single-cell responses in striate cortex of kittens deprived of vision in one eye. J Neurophysiol 26: 1003-1017.

18. Kiorpes L (2006) Visual processing in amblyopia: animal studies. Strabismus 14: 3-10.

19. Löwel S, Singer W (1992) Selection of intrinsic horizontal connections in the visual cortex by correlated neuronal activity. Science 255(5041): 209-212.

20. Kiorpes L, McKee SP (1999) Neural mechanisms underlying amblyopia. Curr Opin Neurobiol 9(4): 480-486.

21. Smith EL, Chino YM, Ni J, Cheng H, Crawford ML, et al. (1997) Residual binocular interactions in the striate cortex of monkeys reared with abnormal binocular vision. J Neurophysiol 78(3): 1353-1362.

22. Zhang B, Bi H, Sakai E, Maruko I, Zheng J, et al. (2005) Rapid plasticity of binocular connections in developing monkey visual cortex (V1). Proc Natl Acad Sci U S A 102(25): 9026-9031.

23. Duffy FH, Burchfiel JL, Conway JL (1976) Bicuculline reversal of deprivation amblyopia in the cat. Nature 260(5548): 256-257.

24. Arden GB, Barnard WM, Mushin AS (1974) Visually evoked responses in amblyopia. Br J Ophthalmol 58(3): 183-192.

25. Sokol S (1983) Abnormal evoked potential latencies in amblyopia. Br J Ophthalmol 67(5): 310-314.

26. McKerral M, Polomeno RC, Leporé F, Lachapelle P (1999) Can interocular pattern reversal visual evoked potential and motor reaction time differences distinguish anisometropic from strabismic amblyopia? Acta Ophthalmol Scand 77(1): 40-44.

27. Levi DM, Klein S (1982) Hyperacuity and amblyopia. Nature 298(5871): 268-270.
28. Levi DM, Klein SA (1985) Vernier acuity, crowding and amblyopia. Vision Res 25(7): 979-991.

29. Levi D (1990) Visual acuity in strabismic and anisometropic amblyopia. Ophthalmololgy Clinics of North America 3: 289-230.

30. Birch EE, Swanson WH (2000) Hyperacuity deficits in anisometropic and strabismic amblyopes with known ages of onset. Vision Res 40(9): 1035-1040.

31. Kiorpes L, Kiper DC, O’Keefe LP, Cavanaugh JR, Movshon JA (1998) Neuronal correlates of amblyopia in the visual cortex of macaque monkeys with experimental strabismus and anisometropia. J Neurosci 18(16): 6411-6424.

32. Kiorpes L, McKee SP (1999) Neural mechanisms underlying amblyopia. Curr Opin Neurobiol 9(4): 480-486.

33. Levi DM, McKee SP, Movshon JA (2011) Visual deficits in anisometropia. Vision Res 51(1): 48-57.

34. McKee SP, Levi DM, Movshon JA (2003) The pattern of visual deficits in amblyopia. J Vis 3(5): 380-405.

35. Hess RF, Mansouri B, Thompson B (2010) A new binocular approach to the treatment of amblyopia in adults well beyond the critical period of visual development. Restor Neurol Neurosci 28(6): 793-802.

36. Hess RF, Mansouri B, Thompson B (2011) Restoration of binocular vision in amblyopia. Strabismus 19(3): 110-118.

37. Li J, Thompson B, Lam CS, Deng D, Chan LY, et al. (2011) The role of suppression in amblyopia. Invest Ophthalmol Vis Sci 52(7): 41694176.

38. Joosse MV, Simonsz HJ, Spekreijse H, Mulder PG, van Minderhout HM (2000) The optimal stimulus to elicit suppression in small-angle convergent strabismus. Strabismus 8(4): 233-242.

39. Dakin SC (2009) Vision: thinking globally, acting locally. Curr Biol 19(18): 851-854

40. Born RT, Bradley DC (2005) Structure and function of visual area MT. Annu Rev Neurosci 28: 157-1589.

41. Hamm LM, Black J, Dai S, Thompson B (2014) Global processing in amblyopia: a review Front Psychol 5: 583.

42. Haxby JV, Grady CL, Horwitz B, Ungerleider LG, Mishkin M, et al. (1991) Dissociation of object and spatial visual processing pathways in human extrastriate cortex. Proc Natl Acad Sci U S A 88(5): 1621-1625.

43. Goodale MA, Milner AD (1992) Separate visual pathways for perception and action. Trends Neurosci 15(1): 20-25.1

44.Van Essen DC, Gallant JL (1994) Neural mechanisms of form and motion processing in the primate visual system. Neuron 13(1): 1-10.

45. Simmers AJ, Ledgeway T, Hess RF, McGraw PV (2003) Deficits to global motion processing in human amblyopia. Vision Res 43(6): 729-738.

46. Goodale MA, Milner AD (1992) Separate visual pathways for perception and action. Trends Neurosci 15(1): 20-25.

47. Merigan WH, Maunsell JH (1993) How parallel are the primate visual pathways? Annu Rev Neurosci 16: 369-402.

48. Simmers AJ, Ledgeway T, Hess RF (2005) The influences of visibility and anomalous integration processes on the perception of global spatial form versus motion in human amblyopia. Vision Res 45(4): 449-460.

49. Husk JS, Hess RF (2013) Global processing of orientation in amblyopia. Vision Res 82: 22-30.

50. Braddick O, Atkinson J, Wattam-Bell J (2003) Normal and anomalous development of visual motion processing: motion coherence and “dorsal-stream vulnerability". Neuropsychologia 41(13): 1769-1784. 
51. Zhou J, Huang PC, Hess RF (2013) Interocular suppression in amblyopia for global orientation processing. J Vis 13(5): 19.

This work is licensed under Creative Commons Attribution 4.0 License

DOI: $10.19080 / J 0 J 0.2017 .05 .555665$
52. Mansouri B, Thompson B, Hess RF (2008) Measurement of suprathreshold binocular interactions in amblyopia. Vision Res 48(28): 2775-2784.

Your next submission with Juniper Publishers will reach you the below assets

- Quality Editorial service

- Swift Peer Review

- Reprints availability

- E-prints Service

- Manuscript Podcast for convenient understanding

- Global attainment for your research

- Manuscript accessibility in different formats

( Pdf, E-pub, Full Text, Audio)

- Unceasing customer service

Track the below URL for one-step submission https://juniperpublishers.com/online-submission.php 